\title{
Cognitive impairment in multiple system atrophy Changing concepts
}

\author{
Agessandro Abrahão, Livia Almeida Dutra, Pedro Braga Neto, José Luiz Pedroso, \\ Ricardo Araújo de Oliveira, Orlando Graziani Povoas Barsottini
}

\begin{abstract}
Multiple system atrophy (MSA) is characterized by a variable combination of cerebellar ataxia, parkinsonism and pyramidal signs associated with autonomic failure. Classically, cognitive impairment was not considered a clinical feature of MSA and dementia was pointed out as an exclusion diagnostic criteria. Based on comprehensive neuropsychological assessment, cognitive impairment was found to be a frequent feature in MSA, and clinically-defined dementia is now reported in $14-16 \%$ of cases. This article reviews the current data on cognitive impairment in MSA along with its neuropsychological profile and pathophysiology.

Key words: multiple system atrophy, cognitive impairment, dementia, atypical parkinsonism, neuropsychological evaluation.
\end{abstract}

\begin{abstract}
Comprometimento cognitivo na atrofia de múltiplos sistemas: mudando os conceitos
Resumo - A Atrofia de Múltiplos Sistemas (AMS) é caracterizada por uma combinação variável de ataxia cerebelar, parkinsonismo e sinais piramidais, associados à disfunção autonômica. Classicamente, o comprometimento cognitivo não é considerado como manifestação clínica da AMS e a demência é apontada como um critério de exclusão para o diagnóstico. Baseado na avaliação neuropsicológica ampla, o comprometimento neuropsicológico revelou-se frequente na AMS e a presença de demência é atualmente descrita em 14-16\% dos casos. Este artigo revisa os dados atuais sobre o comprometimento cognitivo na AMS, seu perfil neuropsicológico e fisiopatologia.

Palavras-chave: atrofia de múltiplos sistemas, comprometimento cognitivo, demência, parkinsonismo atípico, avaliação neuropsicológica.
\end{abstract}

\section{Introduction}

Multiple system atrophy (MSA) is characterized by a variable combination of cerebellar ataxia, parkinsonism and pyramidal signs associated with autonomic failure. The core feature of MSA pathology is the presence of widespread argyrophilic neuronal and glial cytoplasmatic inclusions (GCI) containing $\alpha$-synuclein, which is the obligatory feature for a definite diagnosis. The density of GCIs containing $\alpha$-synuclein correlates significantly with neuronal deterioration and disease duration. Also, another common pathological finding is significant neuronal loss in the basal ganglia, cerebellum, pons, inferior olivary nuclei and spinal cord..$^{1-3}$

The earliest description of sporadic cases presenting with cerebellar ataxia and urinary incontinence dates from
1900 and was reported by Dejerine and Thomas. They introduced the term olivopontocerebellar atrophy for these neurological conditions. ${ }^{4}$ In the years that followed, the concepts of postural hypotension and dysautonomia were incorporated by Shy and Drager, who described a syndrome characterized by orthostatic hypotension, anhidrosis, urinary and fecal incontinence, as well as sexual impotence associated with variable neurological involvement. ${ }^{5,6}$ In the 1960s, cases presenting predominantly with parkinsonism were described as striatonigral degeneration. ${ }^{7,8}$ Finally, the term MSA was proposed by Graham and Oppenheimer to encompass the three conditions above. ${ }^{9}$

The first diagnostic criteria ${ }^{10}$ have indicated that dementia was an exclusion criteria for the diagnosis of MSA. The ensuing updated consensus of $2008^{11}$ considered de-

Division of General Neurology and Ataxias, Department of Neurology and Neurosurgery, Universidade Federal de São Paulo, São Paulo SP, Brazil.

Agessandro Abrahão - Rua Tenente Gomes Ribeiro, 30 / apt. 123 - 04038-040 São Paulo SP - Brazil. E-mail: agessandro@gmail.com

Disclosure: The authors report no conflits of interest.

Received July 3, 2011 Accepted in final form November 2, 2011. 
mentia (as defined by DSM-IV ${ }^{12}$ ) and severe cognitive impairment (according to the Mini Mental State Examination $-\mathrm{MMSE}^{13}$ ) as non-supporting features. However, in the last few years, cognitive impairment was found to be a frequent feature in MSA based on evidence from qualitative neuropsychological assessment. ${ }^{14,15}$ Dementia in MSA is now reported in $14-16 \%$ of cases. ${ }^{14,16}$

In the present report, we review and discuss the current data on cognitive impairment in MSA.

\section{Methods}

A literature search was carried out on the PubMed database analyzing only papers published in English and indexed on Medline up until May, 2011. The following key words were used: multiple system atrophy, striatonigral degeneration, olivopontocerebellar atrophy, memory, cognitive impairment and dementia. From the retrieved articles, a total of 40 papers were included for relevance and encompassed retrospective and prospective studies, case series reports, clinical trials and reviews.

\section{MSA overview}

MSA comprises two categories of clinical manifestations: MSA with predominant parkinsonism (MSA-P) and MSA with predominant cerebellar ataxia (MSA-C). ${ }^{11}$ According to the final report of the European Multiple System Atrophy Study Group (EMSA-SG) ${ }^{17}$ mean age at disease onset was 57.8 years and disease duration at time of diagnosis was 5.8 years. MSA-P represented $68.2 \%$ of European patients and is also more common in the North America. ${ }^{18}$ By contrast, in Japan, MSA-C is more prevalent than MSA-P ( $83.8 \%$ vs. $16.2 \%$ in a cohort of 142 patients $^{19}$ and $67.4 \%$ vs. $32.6 \%$ in a retrospective analysis of 230 Japanese patients). ${ }^{20}$

A consensus statement on the diagnosis of MSA was proposed in $1998^{10}$ and revised in 2008 by Gilman et al. ${ }^{11}$ The latter simplified the previous criteria and incorporated new pathological, laboratory and neuroimaging findings.

Definite MSA diagnosis requires the demonstration of widespread $\alpha$-synuclein-positive GCI and neurodegenerative findings in striatonigral or olivopontocerebellar structures. Probable and possible MSA criteria are listed in Table $1 .{ }^{11}$ Additionally, supporting and non-supporting features for MSA diagnosis are also summarized in Table 1. Of note, dementia is considered a non-supporting feature. ${ }^{11}$

Parkinsonism in MSA shares similar clinical features to Parkinson's disease (PD), such as bradykinesia, rigidity, postural instability and also resting tremor. Transitory response to levodopa may also be seen. On the other hand, when cerebellar syndrome is present, ataxic gait with early falls and ocular movement abnormalities are found. ${ }^{21} \mathrm{Py}-$ ramidal signs occur in almost fifty percent of patients ${ }^{22}$ and dysphagia and dysarthria may appear in early stages. ${ }^{23}$ Dysautonomia may cause erectile dysfunction in male patients, urinary incontinence, constipation, orthostatic blood pressure decline, diaphoresis or cold blue hands. ${ }^{21}$ Dystonia is a supporting feature, especially when anterocollis or Pisa syndrome (axial dystonia with lateral flexion of trunk) are present. ${ }^{3,21}$

In MSA-P, MRI findings include putaminal atrophy, putaminal dorsolateral T2-hypointensity, with "slit-like" marginal T2-hyperintensity. In MSA-C, MRI findings include atrophy of the lower brainstem, pons, middle cerebellar peduncles, and vermis, as well as pontine cruciform hyperintensity on T2-weighted images and diffuse T2-hyperintensity of middle cerebellar peduncles. ${ }^{24}$

\section{Cognitive impairment in MSA}

Early reports - Classically, dementia was considered an exclusion criteria based on analysis of retrospective data. ${ }^{10,15,18,25}$ In this context, MSA diagnosis was ruled out at the first medical interview if significant cognitive impairment was present although no reliable cognition analyses is available from these studies. ${ }^{15}$

Nevertheless, in the early nineties, a few authors reported the occurrence of cognitive impairment in patients with sporadic late-onset ataxia or parkinsonism associated with dysautonomia. In this scenario, Sullivan et al. ${ }^{26}$ reported a 55-year-old woman that presented clinical and neuroimaging features characteristic of MSA-P concomitant with short term memory and language impairment. Consistent data on this issue emerged one year later, when neuropsychological evaluation of sixteen MSA patients disclosed frontal lobe dysfunctions compared to matched controls. ${ }^{27}$

Epidemiology - The frequency of cognitive impairment in MSA patients is highly variable, as are the methods and tools employed for its diagnosis, ranging from bedside clinical impression to comprehensive neuropsychological battery. In a retrospective analysis of 203 pathologicallyconfirmed MSA patients, dementia was found in only one patient, although mild or moderate intellectual impairment was documented in $25 \%$ of patients, based on bedside unstructured impressions. ${ }^{22}$

Results from a Japanese center reported that dementia was found in 10 out of $58 \mathrm{MSA}$ patients evaluated. Although dementia may occur as a late feature of the disease, one Japanese patient presented dementia one-year prior to motor symptoms. Unfortunately no post-mortem examination was performed to confirm a definite diagnosis. ${ }^{27}$ Nevertheless, disease duration correlated weakly with cognitive impairment.

In another retrospective study of pathologically-con- 


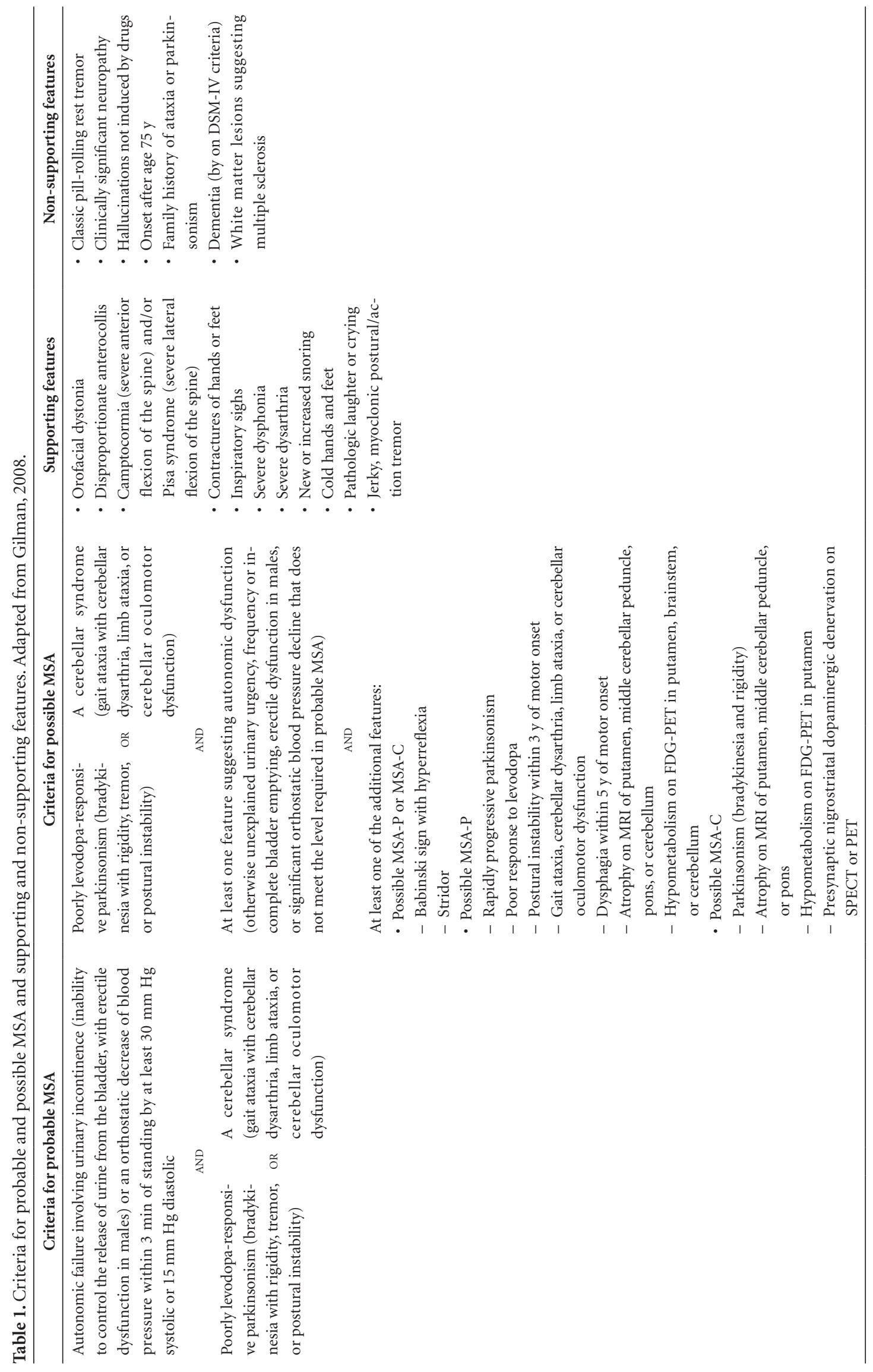


firmed cases, dementia was identified in $15.7 \%$ of 38 MSA patients, typically five years after disease onset. ${ }^{14} \mathrm{O}$ 'Sullivan et al. ${ }^{16}$ demonstrated that 11 patients out of 83 MSA cases were demented, using DSM-IV criteria. The final follow-up analysis of the prospective European cohort (EMSA-SG) published in 2010 revealed that $4.5 \%$ of the patients presented dementia based on MMSE evaluation. ${ }^{17}$ Unfortunately, the MMSE probably underestimated the prevalence of cognitive impairment in this cohort. More substantial evidence that cognitive impairment is consistent with a diagnosis of MSA was found in a prospective neuropsychological analysis of 372 MSA patients published by Brown et al. ${ }^{15}$, in a subgroup analysis of the NNIPPS study (Neuroprotection and Natural History in Parkinson-Plus Syndromes - a randomized, multi-center, double-blind, placebo-controlled study of the efficacy and safety of riluzole in patients with MSA and Progressive Supranuclear Palsy - PSP). In this latter study, the Mattis Dementia Rating Scale (DRS), a broader and more comprehensive neuropsychological battery, disclosed that $19.6 \%$ of MSA patients presented significant cognitive impairment. A single cognitive domain impairment was observed in $28.6 \%$, and multiple domain impairment in 13.5\%, of cases. Moreover, using the Frontal Assessment Battery (FAB), 31.8\% of the patients scored below the cut-off score. Logistic regression revealed that severe motor disability, fewer than 10 years of education, male gender, cardiovascular dysautonomia and absence of genitourinary symptoms were considered predictors of cognitive impairment. This is the largest prospective cohort of patients with MSA studied to date and indicates that a remarkable proportion of these patients have significant cognitive impairment.

Neuropsycological profile in MSA and other parkinsonian syndromes - MSA, PD, and Dementia with Lewy Bodies (DLB) are called synucleinopathies because they share $\alpha$-synuclein inclusions as a neuropathological hallmark. In this group, common clinical features besides parkinsonism, include REM (rapid eye movement) sleep behavior disorder, ${ }^{28}$ dysautonomia symptoms and cognitive impairment, which are well known in early DLB and late PD. When comparing cognitive profiles of synucleinopathies, it is interesting to note that cognitive impairment is more pronounced in DLB and only mild in Parkinson's disease, whereas MSA patients present an intermediate profile. $^{29}$

Impaired cognitive domains in PD include attention, memory, visuo-spatial, constructional, and executive functions. Only PD and DLB patients showed a pattern of severe global impairment in memory and executive function..$^{30}$ On the other hand, MSA patients present involvement of language, non-verbal reasoning, working memory and attention, according to previous studies. There are conflicting data regarding the involvement of visuospatial function and praxis in MSA. ${ }^{29,31-38}$

Patients with MSA-P present severe involvement of visuospatial and constructional function, verbal fluency, and executive function, while MSA-C patients present milder degree of impairment only in visuospatial and constructional function. ${ }^{41}$ In addition, neuropsychological impairment in patients with MSA-P was significantly correlated with a decrease in prefrontal perfusion. However, Burk et al. ${ }^{39}$ demonstrated impaired verbal memory and verbal fluency in 20 MSA-C patients. Despite conflicting data, studies suggest differences in cognitive impairment between MSA-P and MSA-C patients while those patients with MSA-P tend to exhibit broader and more severe impairment in cognitive function compared with patients that have MSA-C. ${ }^{40}$

Neuropsychological performance in MSA-C, one of the causes of olivopontocerebellar atrophy (OPCA), was compared to other causes of OPCA. In this study, four groups were compared: controls, MSA-C, ataxic patients without autonomic failure and negative family history (called sporadic OPCA in the cited study) and positive family history of dominantly inherited OPCA. The MSA-C group scored the lowest results, suggesting that an intrinsic physiopathological mechanism is present in MSA-C, compared to other causes of OPCA. ${ }^{31}$

Progressive Supranuclear Palsy (PSP) constitutes another differential diagnosis of MSA and its typical presentation is characterized by parkinsonism, dystonia, bulbar signs and ocular abnormalities such as ophthalmoparesis. Cognitive function in PSP may be affected in up to $60 \%$ of cases, with prominent deficits in attention and executive function, with verbal fluency being severely affected, as well as deficits in both verbal and non-verbal memory with a relative preservation of recognition. ${ }^{15}$ When comparing MSA and PSP using different instruments such as the FAB, MMSE and Mattis Dementia rating Scale, the profile observed in MSA and PSP were similar, albeit more severe in patients with PSP. ${ }^{15}$

More recently, the general concept of cognitive impairment in parkinsonian syndromes is that, independent of the underlying pathology, a core pattern of cognitive impairment occurs, probably reflecting both cortical and subcortical atrophy and their associated cortical pathological changes. ${ }^{15}$ Neuropsychological assessment serves an important role in providing objective evidence of cognitive impairment to support the clinical diagnosis of dementia. However, its role in differential diagnosis is not conclusive. ${ }^{30}$

Pathophysiology - The occurrence of cognitive impairment and dementia in synucleinopathies is well known. 


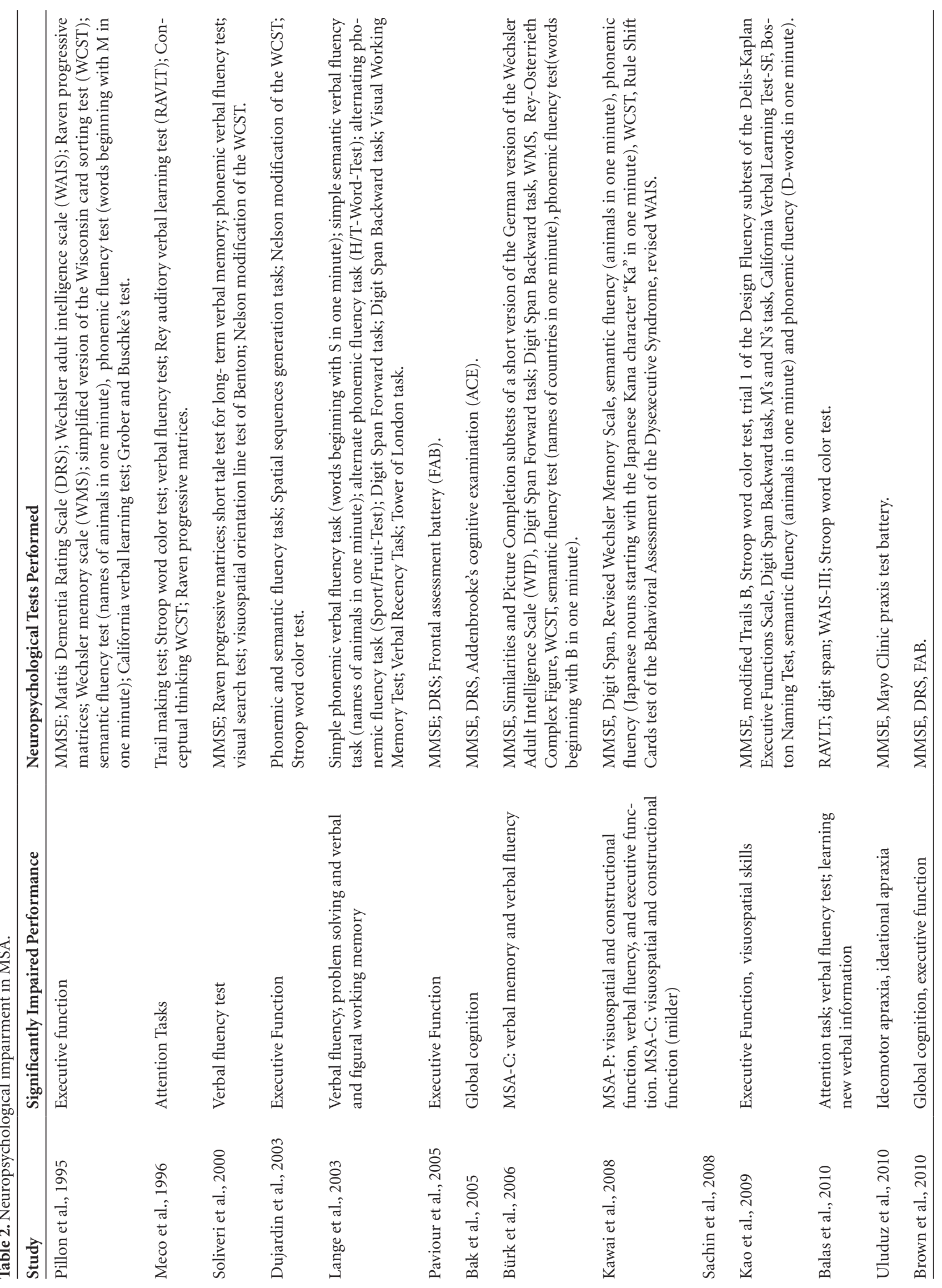


Although DLB, PD and MSA share $\alpha$-synuclein inclusions in their pathophysiology, clinical and neuropsychologic differences are explained by the deposition of these inclusions in variable regions and structures of the brain in each disorder. In PD, Lewy bodies and neurites are found early in the deep brainstem and substantia nigra. Conversely, paralimbic and neocortical structures are affected early in DLB. Finally, in MSA the deep brainstem, cerebellar nuclei, striatal and basal ganglia regions show $\alpha$-synucleinstaining inclusions. ${ }^{32}$ Moreover, $\alpha$-synuclein inclusions are found in neurons in PD and DLB, while in MSA both neuronal intranuclear inclusions and glial cytoplasmic inclusions are present. ${ }^{1,3,32}$

The $\alpha$-synuclein deposition in the striatonigral pathway might justify the occurrence of cognitive impairment in MSA-P, since prefrontal cortex receives afferences from ganglia basal. ${ }^{33}$ On the other hand, the recently described role of cerebellum in cognitive tasks such as working memory, ${ }^{34}$ executive function, ${ }^{35}$ verbal memory, ${ }^{36}$ language, ${ }^{37}$ and attention ${ }^{38}$ offers some explanation for cognitive impairment in patients with MSA-C. Indeed, disruption of cerebellar circuits to prefrontal, posterior parietal, superior temporal and limbic cortices leads to cognitive and behavioral deficits described as Cerebellar Cognitive Affective Syndrome (CCAS), characterized by executive, visuospatial, linguistic and affective disturbances. ${ }^{38}$

Kawamura et al. hypothesized that cognitive impairment in MSA could be influenced by either cerebral hypoperfusion associated with orthostatic hypotension or nocturnal hypoxemia caused by sleep-disordered breathing (SDB), both of which are important clinical symptoms observed in MSA patients. In the cited study however, this hypothesis could not be proven. ${ }^{29}$

Neuropsycological scales - Neuropsychological scales used in the evaluation of cognitive impairment in MSA are highly heterogeneous among published studies. A list of neuropsychological tests used in MSA cognitive evaluation is summarized on Table 2.

MMSE and the DSM-IV are probably not sufficiently sensitive to detect cognitive impairment in MSA. ${ }^{15,41}$ Based on this well-designed prospective study NNIPPS, DRS and FAB provided sensitive and comprehensive information on this issue. Moreover, Bak et al. ${ }^{41}$ showed that Addenbrooke's cognitive examination (ACE) could be as sensitive as DRS.

\section{Conclusion}

Robust data shows that cognitive impairment in MSA is a frequent feature and should be actively pursued. MMSE and DSM-IV criteria for dementia, common tools used in initial clinical evaluation, are not sensitive enough to detect these abnormalities in MSA patients. In this context, comprehensive neuropsychological scales are useful, such as the DRS, FAB and ACE.

The physiopathology of cognitive impairment in this patient group is not well understood, but MSA-P most likely shares the same mechanism involved in others synucleinopathies. However, recent reports show that the cerebellum plays a role in global cognition and this could also be important in MSA-C.

Dementia is still considered a non-supporting feature for MSA diagnosis in the latest consensus. The evidence reviewed in this paper calls for a revision of MSA concepts and diagnostic criteria.

\section{References}

1. Papp MI, Kahn JE, Lantos PL. Glial cytoplasmic inclusions in the CNS of patients with multiple system atrophy (striatonigral degeneration, olivopontocerebellar atrophy and ShyDrager syndrome). J Neurol Sci 1989;94:79-100.

2. Wakabayashi K, Yoshimoto M, Tsuji S, Takahashi H. Alphasynuclein immunoreactivity in glial cytoplasmic inclusions in multiple system atrophy. Neurosci Lett 1998;249:180-182.

3. Stefanova N, Bücke P, Duerr S, Wenning GK. Multiple system atrophy: an update. Lancet Neurol 2009;8:1172-1178.

4. Déjerine J, Thomas A. L'atrophie olivo-ponto-cerebelleuse. Nouv Iconog de le Salpêtrière. 1900;13:330-370.

5. Shy GM, Drager GA. A neurological syndrome associated with orthostatic hypotension: a clinical-pathologic study. Arch Neurol 1960;2:511-527.

6. Quinn N. Multiple system atrophy--the nature of the beast. J Neurol Neurosurg Psychiatry 1989;52(Suppl):78-89.

7. Eecken Hvd, Adams R, Bogaert LV. Striopallidal-nigral degeneration. A hitherto undescribed lesion in paralysis agitans. J Neuropathol Exp Neurol. 1960;19:159-161.

8. Adams RD, Vanbogaert L, Vandereecken H. Striato-Nigral Degeneration. J Neuropathol Exp Neurol 1964;23:584-608.

9. Graham JG, Oppenheimer DR. Orthostatic hypotension and nicotine sensitivity in a case of multiple system atrophy. J Neurol Neurosurg Psychiatry 1969;32:28-34.

10. Gilman S, Low PA, Quinn N, et al. Consensus statement on the diagnosis of multiple system atrophy. J Neurol Sci 1999;163:94-98.

11. Gilman S, Wenning GK, Low PA, et al. Second consensus statement on the diagnosis of multiple system atrophy. Neurology; 2008;71:670-676.

12. American-Psychiatric-Association. Diagnostic and statistical manual of mental disorders (DSM-IV-TR). $4^{\text {th }}$ (text revision); 2000.

13. Folstein MF, Folstein SE, McHugh PR. "Mini-mental state". A practical method for grading the cognitive state of patients for the clinician. J Psychiatr Res 1975; 12:189-198.

14. Wenning GK, Ben-Shlomo Y, Hughes A, Daniel SE, Lees A, 
Quinn NP. What clinical features are most useful to distinguish definite multiple system atrophy from Parkinson's disease? J Neurol Neurosurg Psychiatry 2000;68:434-440.

15. Brown RG, Lacomblez L, Landwehrmeyer BG, et al. Cognitive impairment in patients with multiple system atrophy and progressive supranuclear palsy. Brain 2010;133:2382-2393.

16. O'Sullivan SS, Massey LA, Williams DR, et al. Clinical outcomes of progressive supranuclear palsy and multiple system atrophy. Brain 2008;131.

17. Köllensperger M, Geser F, Ndayisaba J.P, et al. Presentation, diagnosis, and management of multiple system atrophy in Europe: final analysis of the European multiple system atrophy registry. Mov Disord; 2010;25:2604-12.

18. Gilman S, May SJ, Shults CW, et al. The North American Multiple System Atrophy Study Group. J Neural Transm; 2005; 112:1687-1694.

19. Yabe I, Soma H, Takei A, Fujiki N, Yanagihara T, Sasaki H. MSA-C is the predominant clinical phenotype of MSA in Japan: analysis of 142 patients with probable MSA. J Neurol Sci 2006;249:115-121.

20. Watanabe H, Saito Y, Terao S, et al. Progression and prognosis in multiple system atrophy: an analysis of 230 Japanese patients. Brain; 2002;125:1070-1083.

21. Barsottini OG. Parkinsonismo atípico. In: Ferraz B, editor. Doença de Parkinson: prática clínica e terapêutica. São Paulo: Editora Atheneu; 2005.

22. Wenning GK, Tison F, Ben Shlomo Y, Daniel SE, Quinn NP. Multiple system atrophy: a review of 203 pathologically proven cases. Mov Disord 1997;12:133-147.

23. Knopp DB, Barsottini OG, Ferraz HB. Multiple system atrophy speech assessment: study of five cases. Arq Neuropsiquiatr 2002;60:619-623.

24. da Rocha AJ, Maia AC, Jr., da Silva CJ, et al. Pyramidal tract degeneration in multiple system atrophy: the relevance of magnetization transfer imaging. Mov Disord 2007;22:238-244.

25. Geser F, Seppi K, Stampfer-Kountchev M, et al. The European Multiple System Atrophy-Study Group (EMSA-SG). J Neural Transm 2005;112:1677-1686.

26. Sullivan EV, De La Paz R, Z ipursky RB, Pfefferbaum A. Neuropsychological deficits accompanying striatonigral degeneration. J Clin Exp Neuropsychol 1991;13:773-788.

27. Kitayama M, Wada-Isoe K, Irizawa Y, Nakashima K. Assessment of dementia in patients with multiple system atrophy. Eur J Neurol 2009;16:589-594.

28. Boeve BF, Silber MH, Saper CB, et al. Pathophysiology of
REM sleep behaviour disorder and relevance to neurodegenerative disease. Brain 2007;130:2770-2788.

29. Kawamura K, Shimohata T, Nakayama H, Tomita M, Ozawa T, Nishizawa M. Factors influencing the cognitive function in patients with multiple system atrophy. Mov Disord 2010; 25:2891-2892.

30. Emre M, Aarsland D, Brown R, et al. Clinical diagnostic criteria for dementia associated with Parkinson's disease. Mov Disord 2007;22:1689-1707.

31. Berent S, Giordani B, Gilman S, et al. Patterns of neuropsychological performance in multiple system atrophy compared to sporadic and hereditary olivopontocerebellar atrophy. Brain Cogn 2002;50:194-206.

32. Kao AW, Racine CA, Quitania LC, Kramer JH, Christine CW, Miller BL. Cognitive and neuropsychiatric profile of the synucleinopathies: Parkinson disease, dementia with Lewy bodies, and multiple system atrophy. Alzheimer Dis Assoc Disord 2009;23:365-370.

33. Miller BL, Cummings JL. Frontal subcortical circuits. In: Miller BL, Cummings JL, editors. The human frontal lobes : functions and disorders. 2nd ed. ed. New York, N.Y. ; London: Guilford Press; 2007:25.

34. Desmond JE, Gabrieli JD, Wagner AD, Ginier BL, Glover GH. Lobular patterns of cerebellar activation in verbal workingmemory and finger-tapping tasks as revealed by functional MRI. J Neurosci 1997;17:9675-9685.

35. Bellebaum C, Daum I. Cerebellar involvement in executive control. Cerebellum. 2007;6:184-92.

36. Grasby PM, Frith CD, Friston KJ, Bench C, Frackowiak RS, Dolan RJ. Functional mapping of brain areas implicated in auditory--verbal memory function. Brain 1993;116:1-20.

37. Petersen SE, Fox PT, Posner MI, Mintun M, Raichle ME. Positron emission tomographic studies of the cortical anatomy of single-word processing. Nature 1988;331(6157):585-589.

38. Allen G, Buxton RB, Wong EC, Courchesne E. Attentional activation of the cerebellum independent of motor involvement. Science. 1997;275(5308):1940-1943.

39. Bürk K, Daum I, Rüb U. Cognitive function in multiple system atrophy of the cerebellar type. Mov Disord; 2006;21:772-6.

40. Kawai Y, Suenaga M, Takeda A, Ito M, Watanabe H, Tanaka F, et al. Cognitive impairments in multiple system atrophy: MSA-C vs MSA-P. Neurology 2008;70:1390-1396.

41. Bak TH. Cognitive bedside assessment in atypical parkinsonian syndromes. J Neurol Neurosurg Psychiatr 2005;76: 420-422. 